\title{
Spatial Distribution of the N2 and P300 Components of the Auditory Evoked Potential in Women with Arterial Hypertension: A study in the Russian Arctic
}

\author{
Olga V. Krivonogova*, PhD; Elena V. Krivonogova, PhD; Liliya V. Poskotinova, $\mathrm{PhD}, \mathrm{ScD}$ \\ N. Laverov Federal Center for Integrated Arctic Research of the Ural Branch of \\ the Russian Academy of Sciences, Arkhangelsk, the Russian Federation
}

\begin{abstract}
The aim of this study was to evaluate the spatial distribution of the latencies and amplitudes of the N2 and P3 (or P300) components of the auditory evoked potential (AEP) in the Russian Arctic working-age women with different levels of blood pressure (BP).

Methods and Results: A total of 25 working-age women living in Nadym city for more than 20 years took part in this study. Group 1 ( $\mathrm{n}=12$, control group) consisted of women with BP within the normal range $(<130 / 90 \mathrm{mmHg})$; Group 2 ( $\mathrm{n}=13)$ consisted of women with arterial hypertension (AH) (AH duration from 1 to 10 years). The parameters of the N2 and P300) components of the AEP were evaluated using an electroencephalograph (Neuron-Spectrum-4/VPM, Russia). An auditory oddball paradigm was used to elicit the oddball event-related potentials (ERPs).

In Group 2, compared with Group 1, the N2 latency was more pronounced in the parietal (P4, P3), central (C4, C3), frontal (F4, F3), and left temporal (T3, F7) regions. The N2 amplitude in all studied brain regions in individuals of both groups was comparable. The P300 latency did not differ between the two groups. In Group 2, the P300 amplitude was significantly lower in the parietal region (P3) on the left, and in the central and temporal regions on the right (C4, T4). In Group 2, inverse correlations between DBP and the P3 amplitude were revealed in the central $(\mathrm{C} 4: \mathrm{r}=-0.88, P=0.001 ; \mathrm{C} 3: \mathrm{r}=-0.86, P=0.001)$, frontal $(\mathrm{F} 4: \mathrm{r}=-$ $0.76 ; P=0.01 ; \mathrm{F} 3: \mathrm{r}=-0.93, P=0.001)$, and anterior-temporal cerebral regions $(\mathrm{F} 8: \mathrm{r}=-0.65, P=0.04 ; \mathrm{F} 7: \mathrm{r}=-0.64, P=0.04)$. SBP correlated with the $\mathrm{P} 3$ amplitude in the right mid-temporal region (T4: $\mathrm{r}=0.64, P=0.04)$.

Conclusion: The features of the spatial distribution of the N2 and P300 components of the AEP can be used for early diagnosis of the risk of developing cognitive disorders in AH patients.(International Journal of Biomedicine. 2021;11(3):281-285.)
\end{abstract}

Key Words: auditory evoked potential • cognitive impairment $\bullet$ arterial hypertension

For citation: Krivonogova OV, Krivonogova EV, Poskotinova LV. Spatial Distribution of the N2 and P300 Components of the Auditory Evoked Potential in Women with Arterial Hypertension: A study in the Russian Arctic. International Journal of Biomedicine. 2021;11(3):281-285. doi:10.21103/Article11(3)_OA5

\section{Abbreviations}

AH, arterial hypertension; AEP, auditory evoked potential; CI, cognitive impairment; BP, blood pressure; DBP, diastolic BP; SBP, systolic BP; ERP, event-related potential.

\section{Introduction}

Arterial hypertension (AH) is a strong independent risk factor for the development of cognitive impairment and dementia. ${ }^{(1,2)}$ The early detection of cognitive impairments ${ }^{(3,4)}$ is critical for effective treatment and prevention of dementia. However, early detection of cognitive impairment (CI) is a serious clinical problem. The uncomfortable climatic conditions of the Arctic increase the risk of developing $\mathrm{AH}$, and in certain cases may contribute to the development of CI. Neuropsychological methods for detecting cognitive disorders are not always recognized as sufficiently reliable. ${ }^{(5,6)}$

Event-related potentials (ERPs), evoked by the auditory and visual senses, are one of the most commonly used tools 
to assess the neural basis of sensory perception and cognitive processing in humans. ${ }^{(7,8)}$ The associated ERP is composed of several components such as N1, P2, N2, and P3 (or P300), indicating early/pre-attentive to late selective attention and cognitive processing. ${ }^{(9)}$ The $\mathrm{N} 2$ component may reflect the attended mismatch detection, ${ }^{(10)}$ whereas the $\mathrm{P} 3$ component is assumed to be an indicator of controlled processing. ${ }^{(1)} \mathrm{A}$ variety of psychological and biological factors may modulate the latency and amplitude of the ERP components. Shorter latencies indicate superior mental performance relative to longer latencies. Reduced P300 amplitude and latency prolongation have been reported in patients with AH, schizophrenia, and Parkinson's disease. ${ }^{(12-15)}$ Cicconetti et al. ${ }^{(16)}$ showed that the N2 latency was significantly higher in patients with isolated systolic hypertension (ISH) vs. controls $(P<0.0001)$, suggesting the existence of early subclinical alterations in neurocognitive function in early ISH.

$\mathrm{AH}$ in residents of the Arctic zone of Russia is characterized by a more severe course than in residents of middle latitudes. AH also occurs in young people with early damage to target organs, frequent hypertensive crises and impaired higher nervous activity. ${ }^{(17,18)}$ Women make up the active able-bodied part of the population, but the uncomfortable influence of the Arctic climate contributes to early age-related endocrine disorders, ${ }^{(19)}$ which may also affect the state of vascular tone. Therefore, the improvement of instrumental methods for early diagnosis of the risk of cognitive disorders in the working-age residents of the Arctic zone of the Russian Federation, especially in women, is necessary and relevant.

The aim of this study was to evaluate the spatial distribution of the latencies and amplitudes of the N2 and P300 components of the auditory evoked potential (AEP) in the Russian Arctic working-age women with different levels of BP.

\section{Materials and Methods}

A total of 25 working-age women living in Nadym city for more than 20 years took part in this study. Group $1(n=12$, control group) consisted of women with BP within the normal range $(<130 / 90 \mathrm{~mm} \mathrm{Hg})$; Group $2(\mathrm{n}=13)$ consisted of women with $\mathrm{AH}$ ( $\mathrm{AH}$ duration from 1 to 10 years). $\mathrm{AH}$ women either did not adhere to regular antihypertensive therapy $(n=7)$, or periodically received monotherapy $(n=6)$ (angiotensinconverting enzyme inhibitors, angiotensin receptor blockers). The average age of persons in Group I was $43(36.5 ; 55.5)$ years, in Group 2 - 49.0(47.0;53.0) years.

Office BP was measured using a mercury sphygmomanometer, according to Korotkov's method. BP was measured 3 times, and the means of these measurements were used in the analyses.

The parameters of the N2 and P300 components of the AEP were evaluated using an electroencephalograph (NeuronSpectrum-4/VPM, Russia). An auditory oddball paradigm was used to elicit the oddball ERPs. Binaural nonverbal acoustic stimulation was performed with a stimulus duration of $50 \mathrm{~ms}$, an intensity of $80 \mathrm{~dB}$, a period between stimuli of $1 \mathrm{sec}$, a tone frequency of $2000 \mathrm{~Hz}$ (for a target stimulus, probability of $25 \%$ ) and $1000 \mathrm{~Hz}$ (for a non-target stimulus, probability of $75 \%$ ). The P3 was identified as a positive component wave of the
ERP, occurring 250-300 ms after stimulus onset. The N2 was identified as a negative component wave of the ERP, occurring $200 \mathrm{~ms}$ after presentation of stimulus. The amplitude $(\mathrm{mcV})$ and latency (ms) of the N2 and P3 components of the AEP in the brain regions were estimated. The International System 10-20 of the American Society of Electroencephalography was used for electrode placement. The studied brain regions included F3, F4 (frontal), C3, C4 (central), P3, P4 (parietal), and F7, F8, T3, T4 (temporal) leads.

Statistical analysis was performed using the statistical software «Statistica» (v. 13.0, StatSoft, USA). We evaluated the normal distribution of latency and amplitude measures by the Shapiro-Wilks test. Median values are presented with interquartile (IQ) ranges (IQR; 25th to 75th percentiles). Mann-Whitney $U$ test was used to compare differences between two independent groups. The Spearman correlation coefficient $\left(\mathrm{r}_{\mathrm{s}}\right)$ was used to assess the relationship between variables. A value of $P<0.05$ was considered significant.

The study was approved by the Ethics Committee of the N. Laverov Federal Center for Integrated Arctic Research, RAS (Protocol №1, 11.16.2017). Written informed consent was obtained from all participants.

\section{Results}

The SBP and DBP levels in Group 2 were significantly higher than in Group $1(138(133 ; 141) \mathrm{mmHg}$ and $91.5(90 ; 98)$ $\mathrm{mmHg}$ versus $116.5(112.5 ; 126) \mathrm{mmHg}$ and $79.5(76 ; 84.5)$ $\mathrm{mmHg}$, respectively $(P<0.05)$. In Group 2 , compared with Group 1, the N2 latency was more pronounced in the parietal (P4, P3), central (C4, C3), frontal (F4, F3), and left temporal (T3, F7) regions (Table 1). The N2 amplitude in all studied brain regions in individuals of both groups was comparable.

\section{Table 1.}

Spatial distribution of the N2 latency (ms) in the study groups

\begin{tabular}{cccc}
$\left(\boldsymbol{M e}\left(\boldsymbol{P}_{25} ; \boldsymbol{P}_{75}\right)\right.$ & & \\
\hline EEG lead & Group 1 $(\mathrm{n}=12)$ & Group 2(n=13) & $P$-value \\
\hline P4 & $199.5(189.5 ; 214.0)$ & $231.0(214.0 ; 269.0)$ & 0.001 \\
P3 & $200.5(192.0 ; 209.0)$ & $233.5(225.0 ; 247.5)$ & 0.006 \\
C4 & $206.0(192.5 ; 217.0)$ & $241.5(220.0 ; 264.0)$ & 0.006 \\
C3 & $206.0(192.0 ; 217.0)$ & $239.0(231.0 ; 247.0)$ & 0.001 \\
F4 & $209.0(200.5 ; 211.5)$ & $244.5(225.0 ; 269.0)$ & 0.002 \\
F3 & $209.0(200.5 ; 214.0)$ & $250.0(242.0 ; 258.0)$ & 0.001 \\
T4 & $220.0(208.5 ; 220.0)$ & $225.0(203.0 ; 264.0)$ & 0.459 \\
T3 & $203.0(195.0 ; 214.5)$ & $233.5(220.0 ; 258.0)$ & 0.011 \\
F8 & $211.5(206.0 ; 217.0)$ & $228.0(217.0 ; 258.0)$ & 0.054 \\
F7 & $220.0(206.0 ; 220.0)$ & $242.4(225.0 ; 258.0)$ & 0.027 \\
\hline
\end{tabular}


The P300 latency did not differ between the two groups. The range of P300 latency in all brain regions in Groups 1 and 2 was 264-346ms (min-max) and 275-395ms, respectively. In Group 2, the P300 amplitude was significantly lower in the parietal region (P3) on the left, and in the central and temporal regions on the right (C4 T4) (Table 2). In Group 2, the P300 amplitude in the temporal regions was the smallest, at the lower limit of the age standard $(>5 \mathrm{mcV})$.

Table 2.

Spatial distribution of the P300 amplitude (mcV) in the study groups $\left(\mathrm{Me}\left(\mathrm{P}_{25} ; \mathrm{P}_{75}\right)\right.$

\begin{tabular}{cccc}
\hline EEG lead & Group $1(\mathrm{n}=12)$ & Group $2(\mathrm{n}=13)$ & $P$-value \\
\hline P4 & $13.5(9.7 ; 18.0)$ & $8.7(5.0 ; 10.8)$ & 0.067 \\
P3 & $13.9(10.2 ; 19.0)$ & $7.7(5.9 ; 12.9)$ & 0.021 \\
C4 & $17.1(11.3 ; 18.9)$ & $9.4(6.2 ; 15.3)$ & 0.043 \\
C3 & $14.3(10.9 ; 21.5)$ & $7.9(5.5 ; 14.4)$ & 0.067 \\
F4 & $14.1(9.9 ; 23.8)$ & $12.1(7.7 ; 16.8)$ & 0.359 \\
F3 & $11.6(9.7 ; 25.3)$ & $10.4(6.9 ; 14.8)$ & 0.408 \\
T4 & $10.9(7.7 ; 18.3)$ & $6.9(5.4 ; 11.1)$ & 0.04 \\
T3 & $12.6(11.1 ; 17.1)$ & $10.9(6.2 ; 12.9)$ & 0.130 \\
F8 & $8.4(7.5 ; 16.1)$ & $6.9(5.6 ; 9.9)$ & 0.408 \\
F7 & $8.1(6.4 ; 14.2)$ & $6.4(4.7 ; 8.9)$ & 0.161 \\
\hline
\end{tabular}

In Group 2, inverse correlations between DBP and the P300 amplitude were revealed in the central $(\mathrm{C} 4: \mathrm{r}=-0.88$, $P=0.001 ; \mathrm{C} 3: \mathrm{r}=-0.86, P=0.001)$, frontal $(\mathrm{F} 4: \mathrm{r}=-0.76 ; P=0.01$; F3: $\mathrm{r}=-0.93, P=0.001$ ), and anterior-temporal cerebral regions (F8: $\mathrm{r}=-0.65, P=0.04 ; \mathrm{F} 7: \mathrm{r}=-0.64, P=0.04$ ). SBP correlated with the P300 amplitude in the right mid-temporal region (T4: $\mathrm{r}=0.64, P=0.04)$. In Group 1, no significant correlations were found.

Our results showed that in women with $\mathrm{AH}$, the $\mathrm{N} 2$ latency was longer in the parietal $(\mathrm{P} 4, \mathrm{P} 3)$, central $(\mathrm{C} 4, \mathrm{C} 3)$, frontal $(\mathrm{F} 4$, F3), and left temporal (T3, F7) regions of the brain, compared with the control group. The N2 component is associated with the processes of primary recognition and differentiation of the stimulus. ${ }^{(6)}$ According to A.R. Luria's theory, higher cortical functions are provided by the integrated activity of the entire brain as a whole. However, different parts of the brain are not equivalent. ${ }^{(20)}$ In particular, Luria notes that in case of damage to the structures of the functional energy block, which includes the subcortical-stem structures of the brain, the response time to external stimuli increases, which leads to a slowdown in all cognitive processes and a decrease in concentration. ${ }^{(20,21)}$ Another functional block includes the secondary and tertiary zones of the cortical analyzers of somatic sensitivity, hearing, and vision, reflected in the bioelectrical activity of the parietal, temporal, and occipital cerebral lobes. Its function is the perception, recognition, and storage of information received from the outside world. When the structures of this block are damaged, the perception of information (gnosis) is impaired. ${ }^{(20)}$ The third block is responsible for programming actions and decisionmaking with the participation of the frontal cerebral lobes. ${ }^{(21)}$

Lacunar cerebral infarctions with typical localization (thalamus, subcortical basal ganglia) for $\mathrm{AH}$ and diffuse changes in white matter can be the morphofunctional basis of cognitive disorders. ${ }^{(22)}$ Cognitive disorders can also occur against the background of acceleration of degenerative processes in the cerebral cortex. ${ }^{(23)}$ In the case of multiple small-focal lesions of the deep parts of the brain, disorders of higher mental functions are caused by the disconnection of the brain structures, in particular, due to damage to the connections of the frontal regions with the temporal, parietal cerebral regions, as well as the structures of the limbic-reticular complex. ${ }^{(24)}$ Functionally important for cognitive functions are such parts of the brain as the frontal lobes, the temporo-parieto-occipital regions, the mediobasal regions of the temporal lobe, the anterior and middle parts of the visual hillocks associated with the frontal lobes of the brain and the limbic system, the posteriorlower-lateral region and the dentate nucleus of the cerebellar hemisphere, contralateral to the dominant cerebral hemisphere, globus pallidus. ${ }^{(24)}$ All the above morphological and functional changes in the brain are reflected in the spatial distribution of the parameters of all AEP components. Thus, given that the $\mathrm{N} 2$ component reflects the contribution of cortical, thalamic, and stem bioelectric generators, ${ }^{(25)}$ it is assumed that stimulus recognition occurs with the participation of the temporal region with simultaneous connection of the associative parietal lobes of the brain. ${ }^{(26)} \mathrm{A}$ more pronounced lengthening of $\mathrm{N} 2$ latency in the left brain regions in AH persons is possibly associated with a decrease in neuronal activity of central regulators of parasympathetic control of vascular tone, mostly located in the left hemisphere. ${ }^{(27)}$ We believe that in $\mathrm{AH}$ patients, the primary recognition and classification of the stimulus occurs more slowly than in people with normal BP.

The late P3 (P300) component is associated with the final identification of the stimulus that requires comparing it with a pattern in memory and making a decision regarding the action associated with it. Of particular importance in its formation are the processes of directed attention and shortterm memory. ${ }^{(28)}$ As for the physiological aspect of P300 and its relationship with cortical networks, various studies have shown that several cortical generators of $\mathrm{P} 300$ can coexist: the medial temporal lobe, the temporo-parietal junction, and the medial and lateral frontal lobes. ${ }^{(29)}$ The presence of cognitive disorders is characterized by a lengthening of the P300 latency and a decrease in the P300 amplitude. ${ }^{(21)}$ It is believed that the P300 amplitude reflects the relative amount of neuronal resources involved in stimulus processing. ${ }^{(30)}$ The P300 amplitude is also proportional to the amount of attention resources allocated to a specific task and is related to memory performance. ${ }^{(31)}$ In our study, there were no differences in the P300 latency between the AH group and control group, which may indicate the absence of violations of the final identification of the stimulus and decision-making. However, 
a decrease in the P3 amplitude, especially in the temporal regions to marginal values (median 6.4-6.9 $\mu \mathrm{V}$ ), may indicate a change in the activity of the neurotransmitter system, a decrease in the cognitive resource to ensure decision-making. The positive correlations between SBP and P3 amplitude in the right midtemporal region $(\mathrm{r}=0.64, P=0.04)$ that we revealed indicate the need to maintain a relatively elevated $\mathrm{BP}$ for adequate cerebral perfusion and preservation of cognitive functions. However, further preservation of the elevated SBP leads to the risk of CI.

Launer et al. ${ }^{(2)}$ found an increased risk for intermediate and poor cognitive function with every increment increase in SBP by $10 \mathrm{mmHg}$ irrespective of the history of stroke, coronary heart disease, and subclinical atherosclerosis indicating that BP control in early life may reduce the risk for CI in old age.

In our study, inverse correlations between DBP and the P3 amplitude were found in the central, frontal, and anterior temporal regions of both hemispheres. A number of $\mathrm{AH}$ studies $^{(14,15)}$ revealed not only an increase in the P300 latency and a decrease in its amplitude, but also a relationship between changes in $\mathrm{P} 3$ to a greater extent with the DBP level. In a study by Lv et al., ${ }^{(32)} \mathrm{U}$-shaped associations were identified between $\mathrm{CI}$ and SBP, DBP. The cut-points at which risk for CI was minimized were determined by quadratic models as $141 \mathrm{mmHg}$ and $85 \mathrm{mmHg}$, respectively. Below the identified cut-points, each $1 \mathrm{mmHg}$ decrease in $\mathrm{BP}$ corresponded to $0.7 \%$ and $1.1 \%$ greater risk in the risk of $\mathrm{CI}$, respectively. Above the cut-points, each $1 \mathrm{mmHg}$ increase in BP corresponded to $1.2 \%$ and $1.8 \%$ greater risk of CI for SBP and DBP. We believe that the decrease in cognitive resources is more influenced by an increase in DBP, especially in the Arctic zone.

In conclusion, in women with hypertension, the N2 latency is longer in the parietal (P4, P3), central $(\mathrm{C} 4, \mathrm{C} 3)$, frontal (F4, F3) and left temporal regions (T3, F7), and the P3 amplitude is lower in the right central (C4) and midtemporal (T3) regions and the left parietal region of the brain, compared to individuals with normal BP. This may indicate a slowdown in brain processes during the initial recognition and differentiation of stimuli and a decrease in neuronal resources in people with high $\mathrm{BP}$ already at working age. The absence of significant changes in the P300 latency reflects the preservation of the speed of cognitive processes associated with the final identification of the stimulus and decisionmaking. The revealed inverse correlations between DBP and the P300 amplitude in the frontal, central, and anterior temporal regions of the brain reflect the relationship between a decrease in cognitive resources and an increase in DBP. The features of the spatial distribution of the N2 and P300 components of the AEP can be used for early diagnosis of the risk of developing cognitive disorders in $\mathrm{AH}$ patients.

\section{Competing Interests}

The authors declare that they have no competing interests.

\section{Sources of Funding}

The reported study was funded by the FECIAR UrB RAS according to the research project AAAA-A19-119120990083-9.

\section{Acknowledgments}

We would like to thank Dr. D. B. Demin for helping with this research.

\section{References}

1. Cicconetti P, Cacciafesta M, Monteforte G, Thau F, Durante M, Chiarotti F, Ciotti V, Piccirillo GF, Marigliano V. Event-related potentials in the elderly with new mild hypertension. Clin Exp Hypertens. 2000, 22(6):583-593. DOI: 10.1081/ceh-100100093.

2. Launer LJ, Masaki K, Petrovitch H, Foley D, Havlik RJ. The association between midlife blood pressure levels and late-life cognitive function. The Honolulu-Asia Aging Study. JAMA. 1995 Dec 20;274(23):1846-51.

3. Li X, Yan Y, Wei W. Identifying patients with poststroke mild cognitive impairment by pattern recognition of working memory load-related ERP. Comput Math Methods Med. 2013;2013:658501. doi: 10.1155/2013/658501.

4. Grishina DA, Lokshina AB. Diagnosis and treatment of vascular cognitive impairments. Meditsinskiy sovet $=$ Medical Council. 2021;(2):45-54. doi: 10.21518/2079-701X-2021-245-54. [ Article in Russian].

5. Morrison C, Rabipour S, Taler V, Sheppard C, Knoefel F. Visual Event-Related Potentials in Mild Cognitive Impairment and Alzheimer's Disease: A Literature Review. Curr Alzheimer Res. 2019;16(1):67-89. doi: 10.2174/156720 5015666181022101036.

6. Aleshina ED, Koberskaia NN, Damulin IV. [Cognitve evoked potential P300: methodology, experience of use, clinical significance]. Zh Nevrol Psikhiatr Im S S Korsakova. 2009;109(8):77-84. [Article in Russian].

7. Helfrich RF, Knight RT. Cognitive neurophysiology: Event-related potentials. Handb Clin Neurol. 2019;160:543558. doi: 10.1016/B978-0-444-64032-1.00036-9.

8. Modi ME, Sahin M. Translational use of event-related potentials to assess circuit integrity in ASD. Nat Rev Neurol. 2017 Mar;13(3):160-170. doi: 10.1038/nrneurol.2017.15.

9. Lee TW, Yu YW, Wu HC, Chen TJ. Do resting brain dynamics predict oddball evoked-potential? BMC Neurosci. 2011 Nov 24;12:121. doi: 10.1186/1471-2202-12-121.

10. Folstein JR, Van Petten C. Influence of cognitive control and mismatch on the N2 component of the ERP: a review. Psychophysiology. 2008 Jan;45(1):152-70. doi: 10.1111/j.1469-8986.2007.00602.x.

11. Donchin E, Coles MGH. Is the P300 component a manifestation ofcontext updating? Behav Brain Sci. 1988; 11:357-374.

12. Chen KC, Lee IH, Yang YK, Landau S, Chang WH, Chen PS, Lu RB, David AS, Bramon E. P300 waveform and dopamine transporter availability: a controlled EEG and SPECT study in medication-naive patients with schizophrenia and a meta-analysis. Psychol Med. 2014 Jul;44(10):2151-62. doi: $10.1017 / \mathrm{S} 0033291713002808$.

13. Yilmaz FT, Özkaynak SS, Barçin E. Contribution of auditory P300 test to the diagnosis of mild cognitive impairment

*Corresponding author: Olga V. Krivonogova, PhD. Department of Biorhythmology, N. Laverov Federal Center for Integrated Arctic Research of the UrB of the RAS (FCIARctic), Arkhangelsk, Russia.E-mail: ja.olga@gmail.com 
in Parkinson's disease. Neurol Sci. 2017 Dec;38(12):21032109. doi: 10.1007/s10072-017-3106-3.

14. Zueva IB, Vanaeva KI, Sanets EL. [Cognitive evoked potential, p300 component: role in assessment of cognitive function among patients with arterial hypertension and obesityy]. Bulletin SR RAMS. 2012;32(5):55-62. [Article in Russian].

15. Zueva IB, Krivonosov DS, Buch AV. Assessment of cognitive functions using cognitive evoked potential in patients with arterial hypertension. International Heart and Vascular Disease Journal. 2017;5(13):9-12.

16. Cicconetti P, Ciotti V, Tafaro L, Ettorre E, Chiarotti F, Priami C, Cacciafesta M, Marigliano V. Event related brain potentials in elderly patients with recently diagnosed isolated systolic hypertension. Clin Neurophysiol. 2007 Apr;118(4):824-32. doi: 10.1016/j.clinph.2006.11.001.

17. Hasnulin VI, Voevoda MI, Hasnulin PV, Artamonova O G. Modern Approach to Arterial Hypertension in the Circumpolar and Arctic Regions. Literature Review. Ekologiya cheloveka. (Human Ecology). 2016;3:43-51. [Article in Russian].

18. Zapesochnaya IL, Avtandilov AG. The problem of adaptation of the cardiovascular system when living in the Far North: a textbook. SBEI APE "Russian Medical Academy of Postgraduate Education.” M.: SBEI APE RMAPE; 2015. [In Russian].

19. Elfimova A, Tipisova E, Molodovskaya I, Popkova A, Potutkin D. [Sex hormones concentrations at different dopamine levels among women in the Russian Arctic]. Ekologiya cheloveka (Human Ecology). 2020;4;19-25. doi: 10.33396/1728-0869-2020-4-19-25. [Article in Russian].

20. Zakharov VV, Yakhno NN. Cognitive disorders in the elderly and senile age / Methodological guide for doctors. M., 2005. [In Russian].

21. Gnezditsky VV. The inverse problem of EEG and clinical electroencephalography (mapping and localization of sources of electrical activity of the brain). MED Press Inform; 2004. [In Russian].

22. Vakhnina NV. [Cognitive impairment in arterial hypertension]. Meditsinskiy sovet (Medical Council). 2015,
5:34-39. doi: 10.21518/2079-701X-2015-5-34-39. [In Russian]. 23. Parfenov VA, Starchina YuA. Cognitive disorders and their treatment in arterial hypertension. Nervnye bolezni. 2015;1:16-22. [Article in Russian].

24. Fonyakin AV, Geraskina LA, Suslina ZA. Arterial hypertension, cerebrovascular pathology and vascular cognitive disorders. Current issues. Brief guide for doctors. Moscow; 2006. [In Russian].

25. Fitzroy AB, Krizman J, Tierney A, Agouridou M, Kraus $\mathrm{N}$. Longitudinal maturation of auditory cortical function during adolescence. Front Hum Neurosci. 2015 Oct 20;9:530. doi: 10.3389/fnhum.2015.00530.

26. Dzhos YuS, Kalinina LP. Cognitive Event-Related Potentials in Neurophysiology Research (Review). Journal of Medical and Biological Research. 2018, 6(3):223-235. doi: 10.17238/issn2542-1298.2018.6.3.223.

27. Avnon Y, Nitzan M, Sprecher E, Rogowski Z, Yarnitsky D. Autonomic asymmetry in migraine: augmented parasympathetic activation in left unilateral migraineurs. Brain. $2004 \mathrm{Sep} ; 127(\mathrm{Pt}$ 9):2099-108. doi: 10.1093/brain/awh236.

28. Vasilyeva NYu, Zharinov OI, Kuts VA. [Diagnosis of cognitive disorders in patients with arterial hypertension]. Original'nye issledovaniia. 2013;3(4):96. [Article in Russian]. 29. Hansenne M. [The p300 cognitive event-related potential. I. Theoretical and psychobiologic perspectives]. Neurophysiol Clin. 2000 Aug;30(4):191-210. doi: 10.1016/s09877053(00)00223-9. [Article in French].

30. van Dinteren R, Arns M, Jongsma ML, Kessels RP. P300 development across the lifespan: a systematic review and meta-analysis. PLoS One. 2014 Feb 13;9(2):e87347. doi: 10.1371/journal.pone.0087347.

31. Vecchio F, Määttä S. The use of auditory event-related potentials in Alzheimer's disease diagnosis. Int J Alzheimers Dis. 2011;2011:653173. doi: 10.4061/2011/653173.

32. Lv YB, Zhu PF, Yin ZX, Kraus VB, Threapleton D, Chei CL, et al. A U-shaped Association Between Blood Pressure and Cognitive Impairment in Chinese Elderly. J Am Med Dir Assoc. 2017 Feb 1;18(2):193.e7-193.e13. doi: 10.1016/j. jamda.2016.11.011. 